\title{
Sex differences and similarities in the neuroimmune response to central administration of poly $\mathrm{l}: \mathrm{C}$
}

\author{
Caitlin K. Posillico, Rosa E. Garcia-Hernandez and Natalie C. Tronson * (D)
}

\begin{abstract}
Background: The neuroimmune system is required for normal neural processes, including modulation of cognition, emotion, and adaptive behaviors. Aberrant neuroimmune activation is associated with dysregulation of memory and emotion, though the precise mechanisms at play are complex and highly context dependent. Sex differences in neuroimmune activation and function further complicate our understanding of its roles in cognitive and affective regulation.

Methods: Here, we characterized the physiological sickness and inflammatory response of the hippocampus following intracerebroventricular (ICV) administration of a synthetic viral mimic, polyinosinic:polycytidylic acid (poly l:C), in both male and female $\mathrm{C} 57 \mathrm{~B} / 6 \mathrm{~N}$ mice.

Results: We observed that poly l:C induced weight loss, fever, and elevations of cytokine and chemokines in the hippocampus of both sexes. Specifically, we found transient increases in gene expression and protein levels of IL-1a, IL-1 $\beta$, IL-4, IL-6, TNFa, CCL2, and CXCL10, where males showed a greater magnitude of response compared with females. Only males showed increased IFNa and IFNy in response to poly I:C, whereas both males and females exhibited elevations of IFN $\beta$, demonstrating a specific sex difference in the anti-viral response in the hippocampus.

Conclusion: Our data suggest that type I interferons are one potential node mediating sex-specific cytokine responses and neuroimmune effects on cognition. Together, these findings highlight the importance of using both males and females and analyzing a broad set of inflammatory markers in order to identify the precise, sex-specific roles for neuroimmune dysregulation in neurological diseases and disorders.
\end{abstract}

Keywords: Poly l:C, Sex differences, Neuroimmune, Cytokines, Hippocampus, Chemokines, Male, Female, Interferon, Mouse

\section{Background}

The neuroimmune system is responsible for surveying the microenvironment and responding to illness, injury, and infection. It is also required for behavioral responses to infection $[1,2]$ and normal, non-immune neural processes [3-5] including synaptic plasticity and memory formation [6, 7]. Neuroimmune activity in the hypothalamus has a well-described role in physiological responses (e.g., febrile response), and activation in the hippocampus

* Correspondence: ntronson@umich.edu

Psychology Department, University of Michigan, 530 Church St., Ann Arbor MI 48109, USA

\section{$\triangle B M C$}

C C The Author(s). 2021 Open Access This article is licensed under a Creative Commons Attribution 4.0 International License, which permits use, sharing, adaptation, distribution and reproduction in any medium or format, as long as you give appropriate credit to the original author(s) and the source, provide a link to the Creative Commons licence, and indicate if changes were made. The images or other third party material in this article are included in the article's Creative Commons licence, unless indicated otherwise in a credit line to the material. If material is not included in the article's Creative Commons licence and your intended use is not permitted by statutory regulation or exceeds the permitted use, you will need to obtain permission directly from the copyright holder. To view a copy of this licence, visit http://creativecommons.org/licenses/by/4.0/ The Creative Commons Public Domain Dedication waiver (http://creativecommons.org/publicdomain/zero/1.0/) applies to the data made available in this article, unless otherwise stated in a credit line to the data. 
neuroimmune activation impacts cognition and contributes to psychiatric and neurological disorders in both sexes.

Illness, injury, or aseptic triggers of the innate immune system-either bacterial endotoxins (e.g., lipopolysaccharide, LPS) or viral mimics (e.g., polyinosinic:polycytidylic acid, poly I:C) - cause activation of neuroimmune cells, including microglia and astrocytes, and rapid production of cytokines in the brain $[15,16]$. Due to key roles in peripheral inflammation, the cytokines IL- $1 \beta$ [17-19], IL-6 [20-22], and TNF $\alpha$ [23-25] have been the focus of much of the research of neuroimmune function [26]. More recently, other cytokines, including interferons [11, 27], CCL2 [28, 29], and CXCL10 [27, 30, 31] also play critical roles in modulation of behavior, cognition, and affective states, suggesting that many cytokines play important roles in these processes.

Sex differences in immune and neuroimmune activity have also been reported. Females have a greater peripheral immune response compared with males [13]. In contrast, neuroimmune cells in vitro, including astrocytes derived from male cortical tissue, have a significantly greater reaction to inflammatory insults compared with female-derived cells [32, 33]. We have identified sex differences in the magnitude, time course, and pattern of cytokines activated in the hippocampus following peripheral LPS [34], and in the long-lasting impact of LPS on hippocampal function [9]. Thus, sex differences in neuroimmune responses specifically may be a contributing factor to sex differences in neural and cognitive processes and disorders.

Despite incredible advances in psychoneuroimmunology over the past decade, there are critical gaps in our knowledge that preclude a holistic understanding of neuroimmune function and its impacts on cognitive function. First, with some notable exceptions [28, 35, 36 ], studies have typically focused on a few inflammatory cytokines (e.g., IL-1 $\beta$, IL-6, and TNF $\alpha$ ) critical for neuroimmune activation and its effects on cognition. Yet, it is now clear that the massive, coordinated cytokine response observed in the periphery also occurs in the central nervous system [34, 37]. The roles played by other cytokines, and the sex-specific patterns of activation, are yet to be defined [26]. Second, the bulk of studies aimed at understanding neuroimmune activation and its behavioral sequelae have used the gram-negative bacterial shell and toll-like receptor 4 (TLR4) agonist LPS. Nevertheless, viral illnesses-including COVID-19-also trigger changes in behavior, cognition, and emotional states, and significant sex differences have been observed in the context of viral infections $[13,14,38]$-an issue that has been propelled to the forefront during the current COVID-19 pandemic [39, 40]. Given that viruses act through distinct toll-like receptors, their impact is likely mediated by a different, albeit overlapping, pattern of cytokine activation compared with LPS or bacterial triggers. Third, due to its relevance for disease states, many in vivo studies of neuroimmune function use a peripheral immune challenge. Here, neuroimmune activation is primarily driven by peripheral immune signals that infiltrate the brain [41]. This complicates the interpretation of whether sex differences in cytokine levels observed in the brain are due to indirect effects based on sex differences in peripheral immune response or to direct effect of sex differences in neuroimmune function.

In this study, we aimed to identify a broader set of inflammatory cytokines induced in the hippocampus by direct neuroimmune stimulation via central administration of poly I:C in both males and females. We focused on the hippocampus because elevation of hippocampal cytokines is associated with both disruption of memory processes [3, 17, 19, 42-45] and increased depressionlike behaviors [46, 47]. Within the hippocampus, we focused on cytokines and chemokines that have previously been implicated in cognitive and affective dysfunction, including the commonly studied IL- $1 \beta$, IL- 6 , IL-10, and TNF $\alpha$ [48, 49]; as well as IL-4 [50, 51], IL-2 [46, 52], CXCL10 [31, 53], and CCL2 [53]; as well as virusspecific responses (IFN $\alpha$ and IFN $\beta$ [54];); and measures of generic microglial and astrocyte activation (CD11b and GFAP $[55,56] ;)$.

We demonstrate that poly I:C induces fever, weight loss, and changes in mRNA expression and protein levels of cytokines, chemokines, and markers of glial activation across a 24-h period in both sexes. Notably, only IFN $\alpha$ and IFNy showed male-specific patterns of activation after central poly I:C administration, and many cytokines and chemokines showed a greater magnitude increase in males compared with females. Whether these sex differences in neuroimmune activation contribute to sex differences in modulation of cognition and affect and subsequent prevalence of memory- and moodrelated diseases and disorders is an important area of research for our ongoing studies.

\section{Methods \\ Animals}

Ninety-nine male and female 8-9-week-old C57B/6N mice from Envigo (Indianapolis, IN) were used in these experiments. For all experiments, mice were individually housed in standard mouse cages with ad libitum access to food and water in a room with maintained temperature and pressure under a 12:12-h light/dark cycle. All mice had at least 1 week of acclimation to the colony room prior to any manipulations. All protocols were approved by the Institutional Animal Care and Use Committee (IACUC). 


\section{Stereotaxic surgeries}

Bilateral guide cannulae (PlasticsOne, Roanoke, VA) targeting the lateral ventricles were implanted using standard stereotaxic methods (KOPF, Tujunga, CA) at the following coordinates relative to Bregma: $\mathrm{ML} \pm 1.00$ $\mathrm{mm}$, AP $0.30 \mathrm{~mm}$, DV - $2.50 \mathrm{~mm}$. Animals were administered a pre-surgical analgesic $(5 \mathrm{mg} / \mathrm{kg}$ Carprofen, subcutaneous) and anesthetized for surgery using an intraperitoneal injection of $250 \mathrm{mg} / \mathrm{kg}$ of Avertin (2,2,2tribromoethanol) which maintained a surgical plane of anesthesia for the duration of the craniotomy. Bilateral holes were drilled into the skull at the above coordinates, and guide cannulae were implanted using dental cement. Animals were given a second dose of Carprofen ( $5 \mathrm{mg} / \mathrm{kg}$, subcutaneous) $24 \mathrm{~h}$ after surgery to maintain a total of $48 \mathrm{~h}$ of analgesia. Mice were monitored daily for 10 days post-operative and were given at least 2 weeks to recover from surgery prior to use in experiments.

\section{Poly I:C administration}

Polyinosinic:polycytidylic acid (poly I:C; Cat. No. P1530; Sigma-Aldrich, St. Louis, MO) was prepared according to the manufacturer's instructions and sterile-filtered using a $0.22-\mu \mathrm{m}$ filter prior to administration. For intracerebroventricular (ICV) administration, we infused 20 $\mu \mathrm{g}$ of poly I:C (2 $\mu \mathrm{L}$ of $10 \mu \mathrm{g} / \mu \mathrm{L}$ poly I:C) [57] or an equal volume of $0.9 \%$ sterile saline via the implanted guide cannula under brief isoflurane anesthesia.

\section{Sickness behavior assessment}

To confirm the efficacy of the ICV dose of poly I:C, and the specific poly I:C used here [58], poly I:C-induced physiological measures of sickness in males and females were assessed. Body weights and rectal temperatures (RET-3; Physitemp, Clifton, NJ) were measured at 2, 4, $6,12,24$, and $48 \mathrm{~h}$ following ICV administration of poly I:C ( $n=10$ male; $n=9$ female) or sterile saline $(n=10$ male; $n=8$ female; Fig. 2A). Visual and behavioral measures of sickness (piloerections, squinted eyes, hunched posture, and low responsivity) were assessed throughout [59]. No changes in overt sickness behaviors were observed for any experiment (data not shown).

\section{Statistical analysis of sickness behaviors}

Analysis of body weight and temperature changes in response to poly I:C was completed using a mixed repeated-measures ANOVA, using time post-infusion as the within-subjects factor and treatment and sex as the between-subjects factors with Greenhouse-Geisser corrections for sphericity. Significant main effects and interactions $(p<0.05)$ were followed up using post hoc tests with Bonferroni corrections for multiple comparisons, and effect sizes were calculated using the partial eta squared method. Any outliers were identified as samples outside the range of 2 standard deviations from the group mean.

\section{Characterization of the acute hippocampal neuroimmune response}

We used RNA and protein endpoints to examine induction of cytokines and glial activation markers in the hippocampus. Males and females were treated with either poly I:C ( $n=22$ male; $n=24$ female) or sterile saline $(n=8 / \mathrm{sex})$ and brains were collected $0.5 \mathrm{~h}(n=5$ male; $n=6$ female), $2 \mathrm{~h}$ ( $n=6 / \mathrm{sex}), 4 \mathrm{~h}(n=5$ male; $n=$ 6 female), and $24 \mathrm{~h}(n=6 / \mathrm{sex})$ later. All animals were transcardially perfused with $0.1 \mathrm{M}$ phosphate buffer to remove circulating blood from the brain. Both hemispheres of dorsal hippocampus tissue were collected in separate RNase-/DNase-free, sterile microcentrifuge tubes, and immediately flash frozen. All samples were stored at $-80^{\circ} \mathrm{C}$ before tissue processing.

\section{Quantitative real-time $P C R$}

One hemisphere of dorsal hippocampal tissue per mouse was processed for gene expression analysis using quantitative real-time PCR. Frozen samples were homogenized, and messenger RNA (mRNA) was extracted (PureLink RNA Mini Kit; Cat. No. 12183020; Invitrogen, Carlsbad, CA) under sterile, RNase-free conditions. RNA quality was assessed using gel electrophoresis, and UV spectroscopy was used to assess RNA purity (A260/280 > 1.80) and quantity (BioSpectrometer Basic; Eppendorf, Hamburg, Germany). Any genomic DNA in the sample was removed using DNase treatment, and 800 ng of cDNA was synthesized from each mRNA sample (QuantiTect Reverse Transcriptase Kit; Cat. No. 205314; Qiagen, Hilden, Germany). Any samples that did not have a high enough concentration of RNA to make $800 \mathrm{ng}$ of cDNA were removed from further analyses $(n=3$ male; $n=5$ female). Relative gene expression was measured using Power SYBR Green PCR Master Mix (Cat. No. 4368702; Applied Biosystems, Foster City, CA) in $10 \mu \mathrm{L}$ reactions (ABI 7500 real-time PCR system; Cat. No. 4351105; Applied Biosystems).

We measured expression of four commonly used housekeeping genes: 18s, gapdh, hprt1, and rplpo (all QuantiTect Primer Assays: 18s Cat. No. QT02448082, gapdh Cat. No. QT01658692, hprt1 Cat. No. QT00166768, rplp0 Cat. No. QT00249375; Qiagen). We analyzed the relative expression of the following genes of interest: $c c l 2, c d 11 b, c x c l 10$, gfap, ifn $\alpha$, ifn $\beta$, ifn $\gamma$, il-1 $\alpha$, il$1 \beta$, il-6, il-10, and tnfo. The gene primer for $i l-1 \alpha$ was a QuantiTect Primer Assay (Cat. No. QT00113505; Qiagen). The sequences for the remaining gene primers can be found in Table 1 and were ordered through Integrated DNA Technologies and diluted to $0.13 \mu \mathrm{M}$ to be 
used for PCR. All Qiagen primers were diluted as per the manufacturer's instruction.

Housekeeping gene stability analysis To control for the transcriptional activity of the samples being analyzed, we confirmed the stability of four housekeeping genes (18s, gapdh, hprt1, and rplp0). While many studies use common housekeeping genes such as GAPDH or HPRT1, it is less common for authors to report that their chosen housekeeping gene is indeed stable across experimental groups or tissues prior to use in analyses. Thus, we confirmed the stability of our housekeeping genes using a combination of four techniques to ensure the most reliable quantification of gene expression in our studies. First, we assessed the variability of the candidate genes by measuring the standard deviation of the raw quantification cycle $(\mathrm{Cq})$ values from all samples (Fig. 1A). We found that $18 \mathrm{~s}$ had the largest standard deviation of $\mathrm{Cq}$ values (1.540), followed by gapdh (0.527), rplp0 (0.225), and hprt1 (0.151; Fig. 1B). By this approach, rplp0 and hprt1 showed the greatest stability compared to $18 \mathrm{~s}$ and gapdh, with hprt1 exhibiting the lowest variability.

Second, we employed a comparative $\Delta \mathrm{Cq}$ approach in which the standard deviations of the differences in $\mathrm{Cq}$ values $(\Delta \mathrm{Cqs}$ ) between all possible pairs of candidate genes were compared [60] (Fig. 1C). From highest to lowest variability, the genes ranked as follows: $18 \mathrm{~s}$ (1.609 average standard deviation), gapdh (0.911), rplp0 (0.764), and hprt1 (0.753). Again, this method indicated that the most variable genes were $18 \mathrm{~s}$ and gapdh while the most stable genes were rplpO and hprt1, and this is most apparent when considering the lowest $\Delta \mathrm{Cq}$ standard deviation from this method was from the rplpO and hprt1 comparison at 0.206 (Fig. 1D).

The third method we employed was that developed by Vandesompele and colleagues, which calculated the average pairwise variation of one candidate gene with all other candidate genes [61]. We used $R$ packages ReadqPCR and NormqPCR [62] to calculate $M$ stability values, as depicted in Fig. 1E. Consistent with the previous methods, hprt1 and rplpO were the most stable of the candidate genes, with the lowest pairwise variability, $M$ value, of 0.206 .

Fourth, and last, we used a model-based stability analysis approach developed by Andersen et al., an algorithm called NormFinder (v5) [63]. This method protects against identifying two genes via the pairwise approach that might be misinterpreted as being the most stable if they are coregulated. Using this method, again, hprt 1 and $r p l p 0$ were found to be the most stable genes with the lowest expression stability values (Fig. 1F). However, NormFinder resulted in rplpO having the lowest stability value of 0.326 , indicating that the modelbased approach identified $r p l p 0$ as the most stable gene.

Together, these methods identified the two most stable candidate housekeeping genes as hprt1 and rplpO. Vandesompele et al. [61] posits that using the geometric mean of multiple housekeeping genes results in more accurate expression levels of genes of interest. We calculated the geometric mean of the $\mathrm{Cq}$ values from hprt1 and $r p l p O$ to be used in the $2^{-\Delta \Delta C q}$ method for calculations of relative expression for our target genes.

Statistical analysis of mRNA gene expression For each PCR reaction, the quantification cycle $(\mathrm{Cq})$ was determined, and the $2^{-\Delta \Delta C q}$ method was used to calculate the relative gene expression of each gene. Any samples with abnormal amplification curves, melt curves, and/or melt peaks across replicates were removed from analyses $(n=$ $1 /$ sex). Any outliers were identified as samples outside the range of 2 standard deviations from the group mean and excluded from analyses.

Table 1 Primer sequences used for real-time PCR

\begin{tabular}{|c|c|c|c|}
\hline Gene target & $\begin{array}{l}\text { Forward primer } \\
\text { sequence }\left(5^{\prime} \text { to } 3^{\prime}\right)\end{array}$ & $\begin{array}{l}\text { Reverse primer } \\
\text { sequence }\left(5^{\prime} \text { to } 3^{\prime}\right)\end{array}$ & $\begin{array}{l}\text { NCBI reference } \\
\text { sequence }\end{array}$ \\
\hline$c \mathrm{cl} 2$ & CCACAACCACCTCAAGCACT & AAGGCATCACAGTCCGAGT & NM_011333.3 \\
\hline$c d 11 b$ & CGTGAATGGGGACAAACTGAC & GCACTGAGGCTGGCTATTGA & NM_008401.2 \\
\hline cxcl10 & TCCATCACTCCCCTITACCCA & TGGCTTGACCATCATCCTGC & NM_021274.2 \\
\hline gfap & AAACCGCATCACCATTCCTG & CCCGCATCTCCACAGTCTITA & NM_010277.3 \\
\hline ifna & AGAGAAGAAACACAGCCCCT & AGCACATTGGCAGAGGAAGA & NM_010502.2 \\
\hline ifn $\beta$ & GCTCCAAGAAAGGACGAACAT & GGATGGCAAAGGCAGTGTAA & NM_010510.1 \\
\hline ifny & GTCAACAACCCACAGGTCCA & CGACTCCTITTCCGCTTCCT & NM_008337.4 \\
\hline$i l-1 \beta$ & TGCCACCTITGACAGTGATG & GCTCTTGTTGATGTGCTGCT & NM_008361.4 \\
\hline il-6 & GAGACTTCCATCCAGTTGCCT & TCATTTCCACGATTTCCCAGAG & NM_001314054.1 \\
\hline il-10 & CTGGACAACATACTGCTAACCG & AATGCTCCTTGATTTCTGGGC & NM_010548.2 \\
\hline tnfa & ACCCCTTACTCTGACCCCTT & ACTGTCCCAGCATCTTGTGT & NM_001278601.1 \\
\hline
\end{tabular}


A.

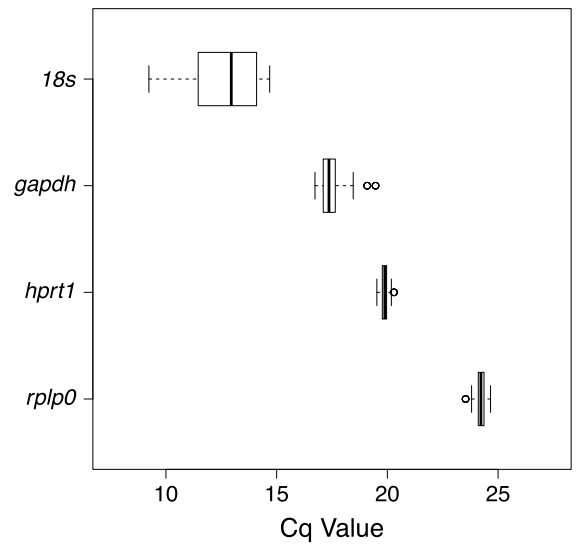

C.

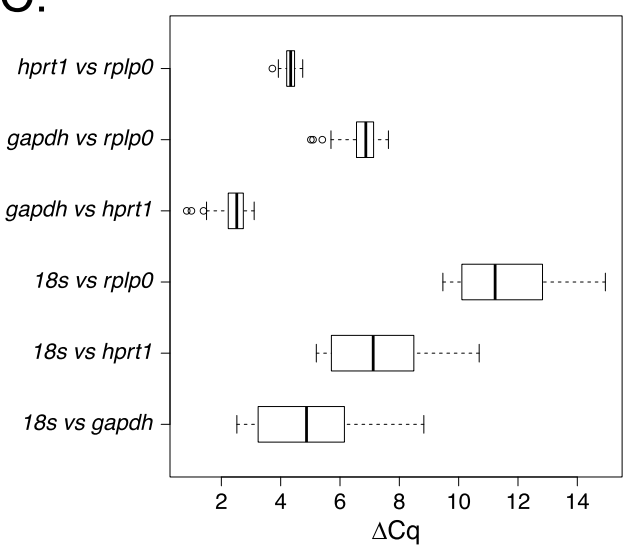

E.

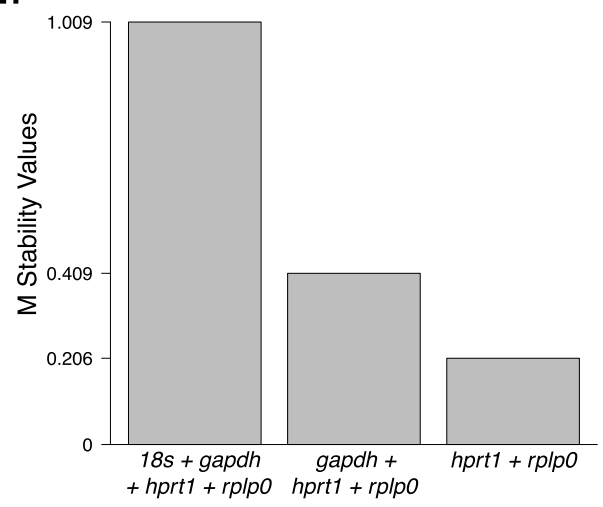

B.

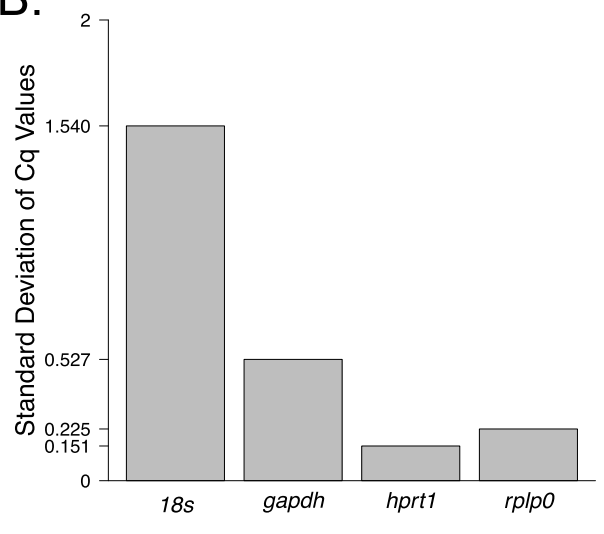

D.

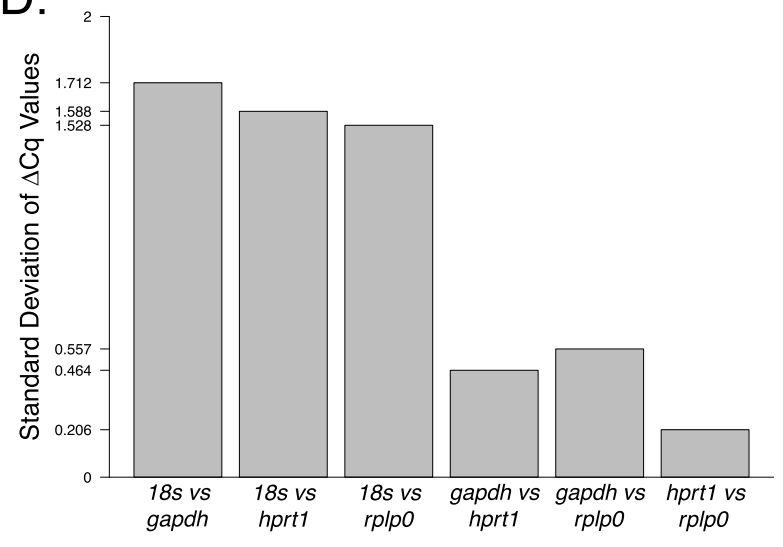

F.

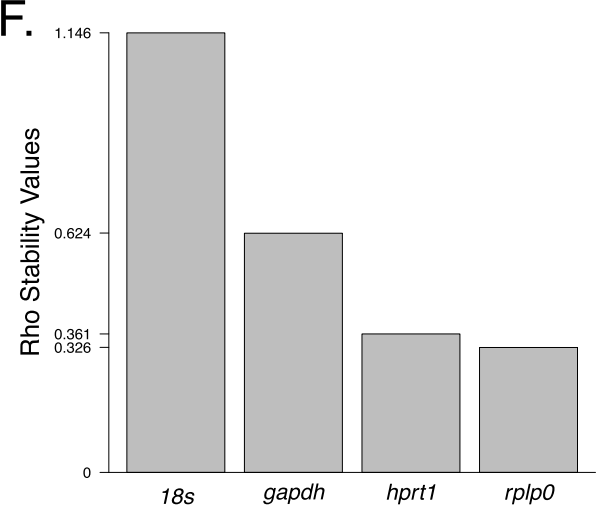

G.

\begin{tabular}{r|c|c|c|c|}
\hline & $\begin{array}{c}\text { Cq Value } \\
\text { Standard Deviations }\end{array}$ & $\begin{array}{c}\text { Avg Standard Deviations } \\
\text { of } \mathbf{\Delta C q} \text { Values }\end{array}$ & M Stability Values & Rho Stability Values \\
\hline $18 s$ & 1.5402440 & 1.609 & 1.609 & 1.1459049 \\
\hline gapdh & 0.5266292 & 0.911 & 0.510 & 0.6235678 \\
\hline hprt1 & 0.1507111 & 0.753 & 0.206 & 0.3610396 \\
rplp0 & 0.2245596 & 0.764 & 0.206 & 0.3256827 \\
\hline
\end{tabular}

Fig. 1 (See legend on next page.) 
(See figure on previous page.)

Fig. 1 Housekeeping gene stability analysis. A Distribution of the quantification cycles (Cq) for housekeeping genes 18s, gapdh, hprt1, and rplp0, with $\mathbf{B}$ associated standard deviations. C Distribution of the difference of $\mathrm{Cq}$ values $(\Delta \mathrm{Cq})$ between pairs of housekeeping genes, and $\mathbf{D}$ the associated standard deviations. E Stability values calculated using gene ratio method by Vandesompele et al. 2002, which uses stepwise elimination of lowest stability (highest $M$ value) to rank gene stability. F Stability values calculated using a model-based approach by Andersen et al. 2004 which measures expression variation such that highest stability results in the lowest Rho value. G Summary of results from each of the four methods of housekeeping gene stability are shown

Baseline sex differences in relative gene expression (qPCR) were assessed by evaluating the male and female saline-treated groups. To directly and meaningfully compare these two groups in the PCR analysis, the male saline-treated group was normalized to the female saline-treated group and analyzed using independent, two-sample $t$ tests.

To appropriately analyze sex differences in relative gene expression (qPCR) across the 24-h time course, we normalized each group to its respective same-sex salinetreated group to control for any sex differences in gene expression at baseline and used two-way ANOVA tests using treatment and sex as factors. Significant main effects and interactions $(p<0.05)$ were followed up using post hoc tests with Bonferroni corrections for multiple comparisons, and effect sizes were calculated using the partial eta squared method.

\section{Multiplex assays}

The second hemispheres of dorsal hippocampal tissue were processed as previously described using lowdetergent RIPA buffer sonication [34]. Milliplex magnetic bead panel assays (CCL2, CXCL10, IFN $\gamma$, IL-1 $\alpha$, IL-1 $\beta$, IL-2, IL-4, IL-6, and IL-10; Millipore Sigma, Burlington, MA) were used as per manufacturer's instructions. Cytokine concentrations were calculated as $\mathrm{pg} / \mathrm{mg}$ of hippocampal tissue via Luminex software. Only samples that showed readable bead counts according to the Luminex software were included in the analyses.

Statistical analysis of protein levels Baseline sex differences in protein levels from multiplex assays were analyzed with independent, two-sample $t$ tests comparing the saline-treated groups. To analyze changes in protein levels from poly I:C across the 24-h time frame, we used two-way ANOVA tests using treatment and sex as factors. Significant main effects and interactions $(p<0.05)$ were followed up using post hoc tests with Bonferroni corrections for multiple comparisons, and effect sizes were calculated using the partial eta squared method. Any outliers were identified as samples outside the range of 2 standard deviations from the group mean and excluded from analyses.

\section{Data visualization and statistical software}

Data visualization and statistical analyses were completed using R 3.6.2 (R Core Team, 2019) with the following packages: dplyr (v0.8.5 [64];), tidyr (v1.0.2 [65];), rstatix (v0.5.0 [66];), DescTools (v0.99.34 [67];), sjstats (v0.17.9 [68];), ReadqPCR and NormqPCR [62], ggplot2 [69], gridExtra (v2.3 [70];), pheatmap (v1.0.12 [71];), and viridis (v0.5.1 [72];).

\section{Results}

\section{Central administration of poly I:C induces physiological sickness responses}

Both females and males showed physiological responses to poly I:C. Whereas both saline- and poly I:C-treated animals showed changes in weight across the 48-h period (Fig. 2B, main effect of Time: $F(3.13,96.92)=$ 28.899, $p<0.001, \eta_{p}^{2}=0.482$ ), poly I:C caused weight loss in both sexes (main effect of Treatment: $F(1,31)=$ 8.781, $p=0.006, \eta_{p}^{2}=0.221$; trend towards a Time $\times$ Treatment interaction: $F(3.13,96.92)=2.476, p=0.064$, $\left.\eta_{p}^{2}=0.074\right)$. Specifically, males and females treated with poly I:C lost significantly more weight than the salinetreated animals at the $12-(p=0.004)$ and 24-h $(p=$ 0.022 ) time points. By $48 \mathrm{~h}$ post-treatment, the weights of poly I:C-treated animals had recovered and were no longer different from those of saline-treated animals $(p$ $=1.00$; Fig. 2B).

In both males and females, poly I:C caused significant increases in body temperature relative to the salinetreated group (Fig. 2C; main effect of Treatment: $F(1$, $31)=23.759, p<0.001, \eta_{p}^{2}=0.434$; Time $\times$ Treatment interaction: $F(4.6,142.62)=11.635, p<0.001, \eta^{2}{ }_{p}=$ 0.273). Post hoc tests revealed that body temperature began to increase $2 \mathrm{~h}$ following poly I:C $(p=0.068)$, remained elevated at the 4- $(p<0.001)$ and 6-h $(p<$ 0.001 ) time points, and recovered to saline-treated body temperatures by $12 \mathrm{~h}$ post-treatment (all $p=1.00$; Fig. $2 \mathrm{C})$. These data, and the similarity of febrile response in males and females, are consistent with previous studies using ICV [57] or systemic [73] poly I:C.

Gene expression of hippocampal cytokines in response to poly I:C is greater in males compared with females Glial activation markers

Poly I:C treatment significantly increased expression of both $c d 11 b$ and $g f a p$, although this appeared to be true 
A.

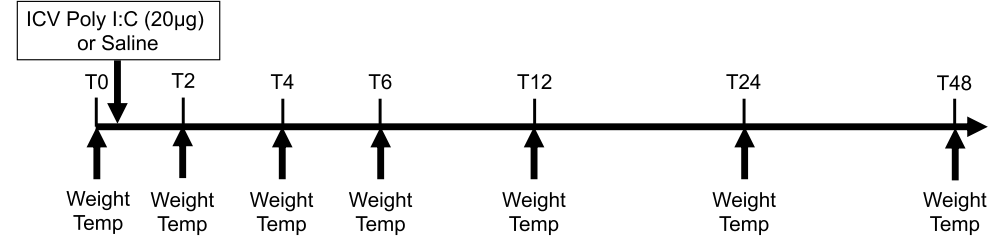

B.

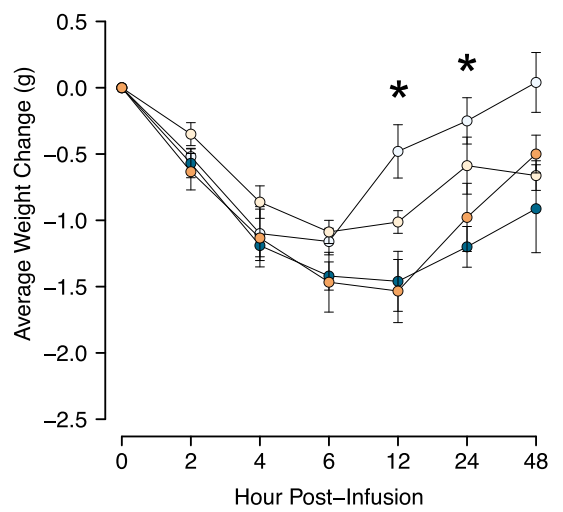

C.

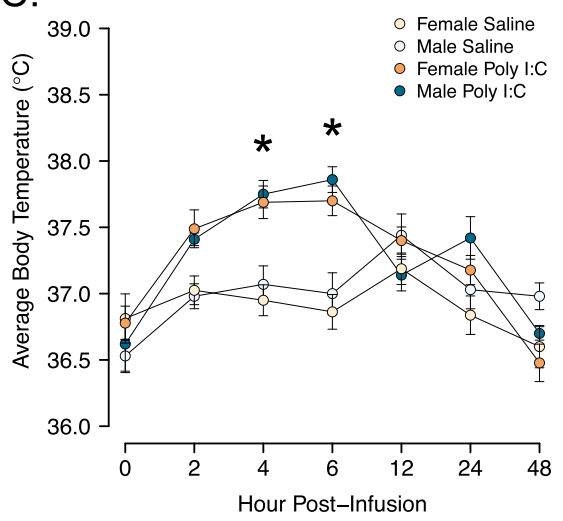

Fig. 2 Analysis of sickness behaviors following poly I:C administration. A Timeline of body weight and temperature measurements following poly I:C or sterile saline administration. B Average weight change from baseline (Time $=0 \mathrm{~h}$ ) prior to treatment. C Average body temperature as measured via rectal thermometer. Analyzed using mixed repeated-measures ANOVA. ${ }^{*} p<0.05$ poly l:C- vs saline-treated groups

only at the 24-h time point (Fig. 3A2, B2, respectively; $c d 11 b$ main effect of Treatment: $F(4,42)=12.96, p<$ 0.001, $\eta_{p}^{2}=0.552$; gfap main effect of Treatment: $F(4$, $\left.42)=12.992, p<0.001, \eta_{p}^{2}=0.553\right)$. Sex did not affect the response of either $c d 11 b$ or gfap to poly I:C (Sex $\times$ Treatment interactions: $c d 11 b: F(4,42)=0.684, p=$ 0.607; gfap: $F(4,42)=0.923, p=0.460)$.

\section{Interleukins}

Poly I:C caused increased expression of $i l-1 \alpha$, il-1 $1 \beta$, and il-6 in both males and females (Fig. 3C2, D2, E2, respectively; main effects of Treatment: il-1 $\alpha: F(4,42)=9.784$, $p<0.001, \eta^{2} p=0.482$; il-1ß: $F(4,42)=9.512, p<0.001$, $\eta_{p}^{2}=0.475$; il-6: $F(4,42)=22.28, p<0.001, \eta_{p}^{2}=$ 0.680). In males, expression began to increase at the $2-\mathrm{h}$ time point following poly I:C treatment for $i l-1 \alpha(p=$ 0.015; Fig. 3C2), il-1 $(p=0.057$; Fig. 3D2), and il-6 ( $p=$ 0.029; Fig. 3E2), showed peaks at the 4-h time point $(p<$ 0.001 for all), and decreased to saline-treated levels by $24 \mathrm{~h}$ ( $p=1.00$ for all). Each of these genes also showed an overall greater expression in males than females (main effects of Sex: $i l-1 \alpha: F(1,42)=6.398, p=0.015$, $\eta_{p}^{2}=0.132 ; i l-1 \beta: F(1,42)=6.695, p=0.013, \eta_{p}^{2}=$ 0.137; il-6: $\left.F(1,42)=21.1, p<0.001, \eta^{2}{ }_{p}=0.334\right)$, and a significantly greater magnitude of response in males compared with females (Sex $\times$ Treatment interactions: $i l-1 \alpha: F(4,42)=3.103, p=0.025, \eta^{2} p=0.228 ; i l-1 \beta: F(4$, 42) $=4.288, p=0.005, \eta_{p}^{2}=0.290 ;$ il-6: $F(4,42)=15, p$ $\left.<0.001, \eta_{p}^{2}=0.588\right)$. Post hoc tests revealed for all three genes, males exhibited an even greater response at only the 4-h time point compared with females $(p<0.05$ for all). Notably, the peak $i l-1 \alpha$ and $i l-1 \beta$ expression in males was roughly 3 -fold higher than that of the peak female expression for these cytokines, and the il-6 peak expression in males was more than 10-fold higher than that of females (Fig. 3C2, D2, E2, respectively).

Males showed greater il-10 gene expression across all time points compared with females (Fig. 3F2; main effect of Sex: $\left.F(1,39)=25.642, p<0.001, \eta_{p}^{2}=0.397\right)$. Additionally, poly I:C significantly increased gene expression of il-10 in males, but not females (Sex $\times$ Treatment interaction: $\left.F(4,39)=3.304, p=0.02, \eta_{p}^{2}=0.253\right)$. Specifically, male expression of $i l-10$ at the 4-h time point following poly I:C was significantly greater than that of saline-treated controls $(p=0.001)$, and this was also greater than the 4 -h expression in females $(p=0.001$; Fig. 3F2).

\section{Interferons}

Both ifn $\alpha$ and ifny showed a similar response pattern to poly I:C, whereby males treated with poly I:C exhibited a significant acute increase in gene expression of both cytokines, but females did not show the same response (Fig. 3G2, I2, respectively; ifno: main effect of Treatment: $F(4,42)=5.007, p=0.002, \eta_{p}^{2}=0.323$; Sex $\times$ Treatment interaction: $F(4,42)=3.35, p=0.018, \eta_{p}^{2}=0.242$; ifn $\gamma$ : 


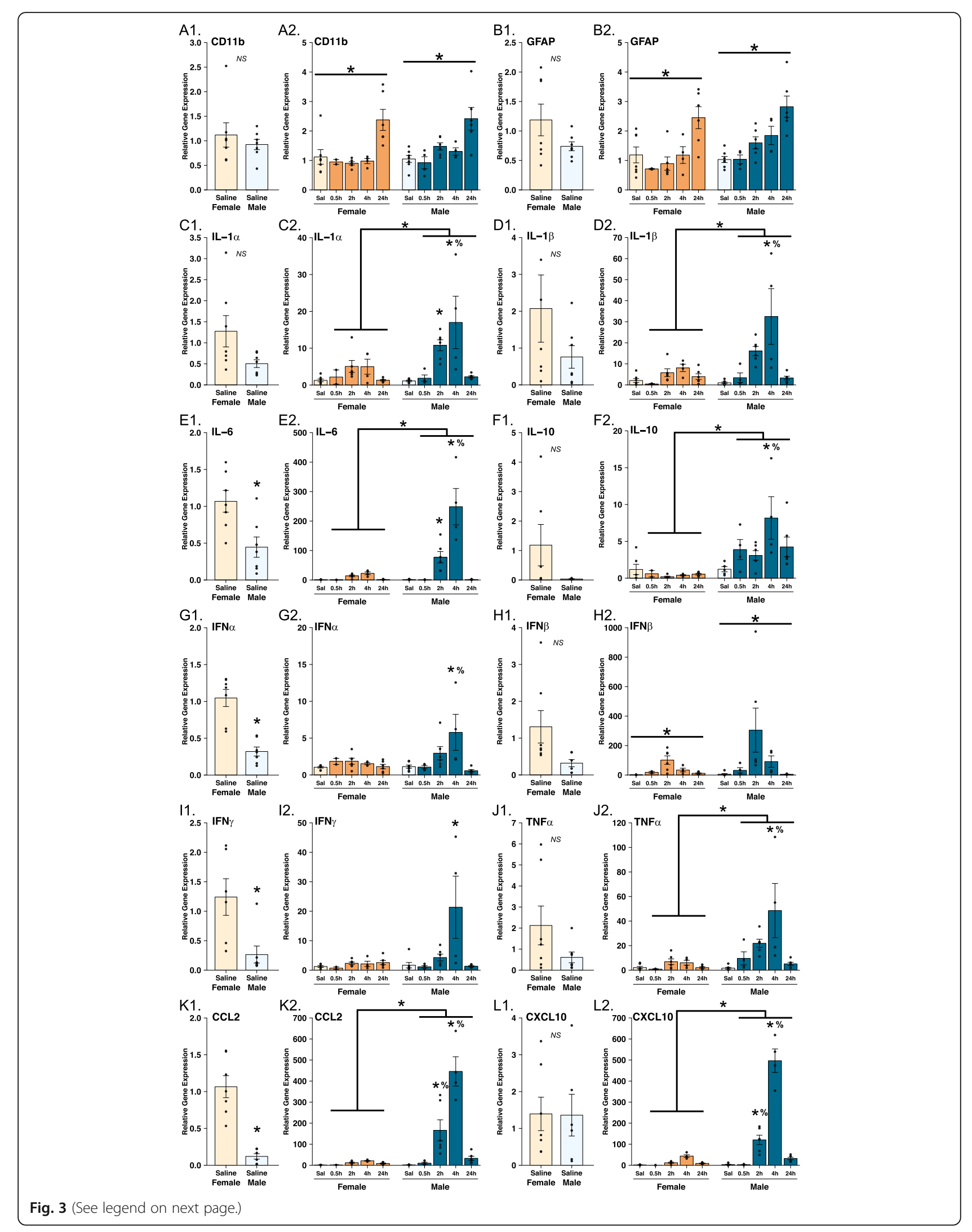


(See figure on previous page.)

Fig. 3 mRNA gene expression of cytokines, chemokines, and markers of glial activation in the hippocampus. Baseline gene expression was measured by normalizing the male saline-treated group to the female saline-treated group and analyzed using independent, two-sample $t$ tests.

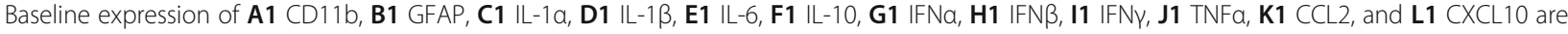
shown. Gene expression changes following poly I:C treatment were calculated by normalizing time points after poly I:C treatment to the salinetreated groups within sex to eliminate confounding variables of baseline sex differences. Gene expression was analyzed using two-way ANOVA tests for A2 CD1 1b, B2 GFAP, C2 IL-1a, D2 IL-13, E2 IL-6, F2 IL-10, G2 IFNa, H2 IFNß, I2 IFNY, J2 TNFa, K2 CCL2, and L2 CXCL10. * above a bracket covering both sexes indicates a significant main effect of sex $(p<0.05) ;{ }^{*}$ above a horizontal line covering just one sex indicates a significant main effect of treatment $(p<0.0 .5) ; *$ above a single bar indicates a significant post hoc test $(p<0.05)$ vs the saline-treated group within sex; $\%$ above a single bar indicates a significant post hoc test $(p<0.05)$ vs females at the same time point

main effect of Treatment: $F(4,40)=4.698, p=0.003$, $\eta_{p}^{2}=0.32$; Sex $\times$ Treatment interaction: $F(4,40)=$ $\left.4.178, p=0.006, \eta_{p}^{2}=0.295\right)$. Specifically, $4 \mathrm{~h}$ after poly I:C treatment, males showed significantly elevated expression compared to the saline-treated controls (ifn $\alpha: p$ $=0.001$; ifn $\gamma: p=0.0001$ ), and this was greater in magnitude than the 4-h time point in females (ifn $\alpha: p=0.014$; ifny: $p=0.001$; Fig. 3G2, I2, respectively). Female ifn $\alpha$ and ifny did not respond to poly I:C treatment at any time point.

In contrast, ifn $\beta$ showed a transient increase in both males and females, and there were no sex differences in magnitude of expression increase (Fig. 3H2; main effect of Treatment: $F(4,42)=4.855, p=0.003, \eta_{p}^{2}=0.316$; Sex $\times$ Treatment interaction: $F(4,42)=1.297, p=$ 0.287). Unlike all other cytokines examined in this study, peak expression appeared to be at the 2-h time point, and expression began decreasing again by $4 \mathrm{~h}$ posttreatment. The magnitude increase was also notable, with a 100-fold increase in females and a 300 -fold increase in males.

\section{Tumor necrosis factor alpha}

Gene expression of $\operatorname{tnf} \alpha$ increased in response to poly I: $\mathrm{C}$, males had significantly higher expression than females overall, and males showed a greater magnitude of response compared with females (Fig. 3J2; main effect of Treatment: $F(4,42)=6.407, p=0.0004, \eta_{p}^{2}=0.379$; main effect of Sex: $F(1,42)=10.1, p=0.003, \eta_{p}^{2}=$ 0.194; Sex $\times$ Treatment interaction: $F(4,42)=4.117, p=$ $0.007, \eta_{p}^{2}=0.282$ ). Post hoc tests showed that males $4 \mathrm{~h}$ post-treatment had significantly greater expression than those treated with saline $(p<0.001)$, and this was again greater than the 4-h peak expression in females $(p=$ 0.001; Fig. 3J2).

\section{Chemokines}

Poly I:C significantly increased the expression of both ccl2 and cxcl10 in males and females, with a peak increase in expression at 4-h post-infusion (Fig. 3K2, L2, respectively; main effects of Treatment: $c c l 2: F(4,41)=$ 25.47, $p<0.001, \eta^{2}{ }_{p}=0.713 ; \operatorname{cxcl10:} F(4,42)=87.37, p$ $\left.<0.001, \eta_{p}^{2}=0.893\right)$.
Expression of both $c c l 2$ and $c x c l 10$ was greater overall in males compared with females (Fig. 3K2, 3L2, respectively; main effects of Sex: ccl2: $F(1,41)=44.55, p<$ 0.001, $\eta_{p}^{2}=0.521 ; \operatorname{cxcl10}: F(1,42)=92.79, p<0.001$, $\eta_{p}^{2}=0.688$ ); and males showed a markedly greater magnitude of response than did females for both chemokines (Sex $\times$ Treatment interactions: $c c l 2: F(4,41)=20.96, p<$ 0.001, $\eta_{p}^{2}=0.672 ; \operatorname{cxcl10:} F(4,42)=60.51, p<0.001$, $\eta_{p}^{2}=0.852$ ).

Remarkably, male $c c l 2$ expression peaked at nearly 450-fold greater than the expression of saline-treated males compared to a roughly 20 -fold increased peak in females (Fig. 3K2). Similarly, cxcl10 expression in males peaked at nearly 500 -times that of saline-treated males while female cxcl10 expression peaked at just over 40times greater than saline-treated females (Fig. 3L2). These massive increases in gene expression are reflected in the strong effect sizes noted for the interaction effect above. Post hoc tests confirmed that the male 2- and 4-h time points post-treatment showed significantly greater gene expression of both $c c l 2$ and $c x c l 10$ than salinetreated males (Fig. 3K2, L2, respectively; $p<0.001$ ). Additionally, both the male 2- and 4-h time points of both genes proved to be significantly greater than the 2and 4-h time points in females, respectively (Fig. 3K2, $\mathrm{L} 2$, respectively; $p<0.01$ ).

\section{Cytokine protein levels in males and females after poly}

$\mathrm{I}: \mathrm{C}$

\section{Interleukins}

IL-1 $\alpha$, IL-1 $\beta$, IL-4, and IL-6 significantly increased following ICV poly I:C administration in both males and females (Fig. 4A-E, respectively; main effects of Treatment: IL-1 $\alpha: F(4,51)=3.523, p=0.013, \eta_{p}^{2}=0.216$; IL$1 \beta: F(4,51)=5.721, p=0.001, \eta_{p}^{2}=0.31$; IL-4: $F(4,51)$ $=5.146, p=0.001, \eta^{2}=0.288 ;$ IL-6: $F(4,51)=10.298, p$ $\left.<0.001, \eta^{2} p=0.447\right)$. In all cases, protein levels increase to a peak $4 \mathrm{~h}$ following poly I:C, similar to the effects seen in mRNA expression.

Both IL- 4 and IL- $1 \beta$ also exhibited a main effect of sex such that protein levels of these cytokines, regardless of time point, were significantly higher in females compared with males (Fig. 4C, D, respectively; IL-4: $F(1,51)$ 


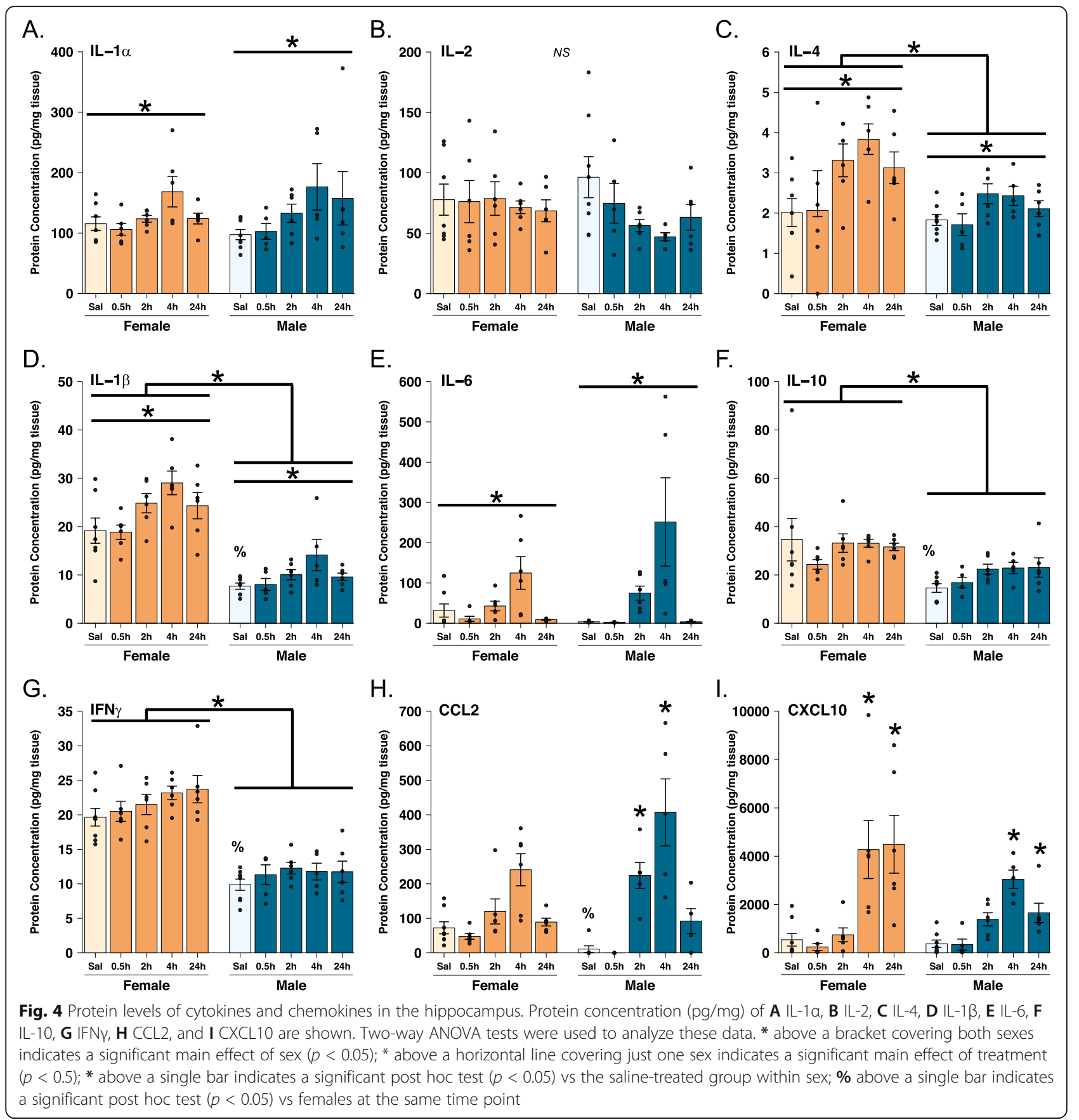

$=11.03, p=0.002, \eta_{p}^{2}=0.178 ;$ IL-1 $1: F(1,51)=$ 114.226, $p<0.001, \eta_{p}^{2}=0.691$.

No interactions of sex and treatment were found for any of the interleukin cytokines examined here (Fig. 4AE; IL-1 $\alpha: F(4,51)=0.446, p=0.775$; IL-2: $F(4,51)=$ $0.987, p=0.423$; IL-4: $F(4,51)=0.982, p=0.426$; IL-1 $\beta$ : $F(4,51)=0.513, p=0.726$; IL-6: $F(4,51)=1.779, p=$ $0.148)$.

Neither IL-2 nor IL-10 showed any effects of poly I:C treatment in either sex (Fig. 4B, F, respectively; main effects of Treatment: IL-2: $F(4,51)=1.498, p=0.217$; IL-10: $F(4,51)=1.122, p=0.357)$. However, females had overall higher levels of IL-10 than did males (Fig. 4F; main effect of Sex; $F(1,51)=20.27, p<0.001, \eta_{p}^{2}=$ $0.284)$.

\section{Interferons}

Unlike mRNA expression, IFN $\gamma$ protein levels did not change following poly I:C administration in either sex (Fig. 4G; main effect of Treatment: $F(4,52)=1.93, p=$ 
0.119). However, IFN $\gamma$ protein levels were higher in females relative to males (Fig. 4G; main effect of Sex: $F(1$, 52) $\left.=150.64, p<0.001 ; \eta_{p}^{2}=0.743\right)$. This was consistent with mRNA expression data where saline-treated females also showed significantly higher expression of ifny at baseline than did males (see Fig. 3I2).

\section{Chemokines}

Both CCL2 and CXCL10 were significantly increased in the hippocampus by ICV poly I:C and in different ways in males and females (Fig. 4H, I, respectively; CCL2: main effect of Treatment: $F(4,46)=18.517, p<0.001$, $\eta_{p}^{2}=0.617$; Sex $\times$ Treatment interaction: $F(4,46)=$ 3.381, $p=0.017, \eta_{p}^{2}=0.227$; CXCL10: main effect of Treatment $F(4,52)=14.54, p<0.001, \eta^{2}{ }_{p}=0.528$; Sex $\times$ Treatment interaction: $F(4,52)=2.796, p=0.035, \eta^{2}{ }_{p}=$ $0.177)$.

In males, CCL2 levels increased earlier (at $2 \mathrm{~h}$ ) postinfusion than females (male saline vs $2 \mathrm{~h} p=0.014$; female saline vs $2 \mathrm{~h} p=1.00$; Fig. $4 \mathrm{H}$ ). For CXCL10, females took longer for protein levels to begin to decrease as compared to the time course in males, with females still showing the massive elevation at $24 \mathrm{~h}$ post-infusion as they did at $4 \mathrm{~h}$ (Fig. 4I).

Notably, CCL2 and CXCL10 levels showed the most substantial increases out of all cytokines measured in protein analysis in the hippocampus. CCL2 levels induced by poly I:C peaked at approximately 4 times that of the saline-treated animals in females and nearly 8 times that of saline-treated males (Fig. 4H). For CXCL10 levels rose roughly 16-fold in females, and 12-fold in males after poly I:C administration (Fig. 4I).

Baseline sex differences in mRNA expression and protein levels of select hippocampal immune molecules

Understanding baseline differences in neuroimmune gene expression and protein levels is essential for understanding sex differences in neuroimmune activation. We found that several cytokines and other immune markers showed greater than 2-fold higher levels at baseline (in saline-treated mice) in females compared with males, and in both gene expression and protein. In contrast, none of the markers examined here were higher in males than in females in either mRNA or protein levels at baseline. This is notable given that we observed the opposite pattern in activation, where males showed stronger poly I:C-induced activation of many cytokines.

\section{Markers with significantly higher baseline levels in females compared with males}

mRNA expression of $i l-1 \alpha$ exhibited a trend towards greater baseline expression in females (Fig. $3 \mathrm{C} 1 ; t(12)=$ 2.006, $p=0.068$ ), and il-6 showed a significantly higher level in females compared with males (Fig. 3E1; $t(11)=$
$3.079, p=0.01,95 \%$ CI $[0.182,1.062])$. However, these gene expression differences were not reflected at the level of protein (Fig. 4A, E).

In contrast, although $i l-1 b$ and $i l-10$ showed no difference in gene expression between the sexes (Fig. 3D1, F1, respectively; il-1ß: $t(12)=1.365, p=0.197$; il-10: $t(9)=$ 1.480, $p=0.173$ ), females had significantly higher protein levels of both IL-1 $\beta$ and IL-10 than males (Fig. 4D, F, respectively; IL-1 $\beta: t(13)=4.275, p=0.001,95 \% \mathrm{CI}$ [5.682, 17.291]; IL-10: $t(13)=2.236, p=0.044,95 \% \mathrm{CI}$ $[0.672,39.314])$.

Two interferons (IFN), ifna and ifny, also showed higher relative mRNA expression levels in females com-

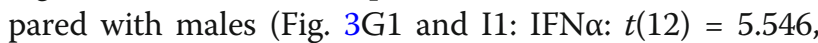
$p=0.0001,95 \%$ CI $[0.441,1.01]$; IFN $\gamma: t(11)=2.995, p=$ 0.012 , 95\% CI $[0.259,1.694])$. Likewise, protein levels of IFN $\gamma$ were higher in saline-treated groups compared with males (Fig. 4G; $t(14)=6.475, p<0.001,95 \% \mathrm{CI}$ $[6.534,13.006])$.

Expression of chemokine $c c l 2$ also showed higher levels of both baseline gene expression (Fig. 3K1; $t(12)=$ 3.287, $p=0.006,95 \%$ CI $[0.259,1.279])$, and protein levels (Fig. $4 \mathrm{H} ; t(12)=2.751, p=0.018,95 \%$ CI $[12.798$, 110.318]) in females compared with males.

\section{Neuroimmune markers with no sex differences in baseline levels}

Neither the microglial activation marker $c d 11 b$ nor the astrocyte activation marker gfap showed sex differences in gene expression in the saline-treated groups (Fig. $3 \mathrm{~A} 1, \mathrm{~B} 1$, respectively; $c d 11 b: t(12)=0.723, p=0.483$; gfap: $t(12)=1.603, p=0.135)$.

Levels of IL-2 and IL-4 protein did not differ between males and females (Fig. 3B, C, respectively, IL-2: $t(12)=$ - 0.832, $p=0.420$; IL-4: $t(13)=0.489, p=0.633)$; nor were there differences in tumor necrosis factor (tnf) $\alpha$ gene expression $(t(12)=1.585, p=0.139)$. Finally, CXCL10 did not differ between the sexes in either mRNA (Fig. 3L1; $t(12)=-0.923, p=0.374$ ) or protein (Fig. 4I; $t(14)=0.548, p=0.592$ ).

\section{Summary of mRNA and protein data}

Overall, hippocampal mRNA expression and protein levels of most of the cytokines and chemokines examined in this experiment responded to central administration of poly I:C in both males and females. We found significant sex differences in baseline mRNA expression and protein levels of several cytokines, where females showed greater basal levels than males. In addition, we found the magnitude of mRNA expression increases was greater in males than females. Protein data showed this to be true only for 2 chemokines, CCL2 and CXCL10.

The heatmaps shown in Fig. 5 indicate that most of the immune signaling molecules affected in the 
A.

\section{mRNA Data}

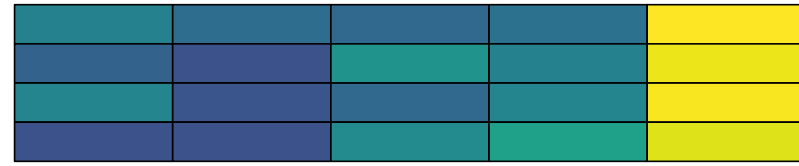

CD11b Female

CD11b Male

GFAP Female

GFAP Male

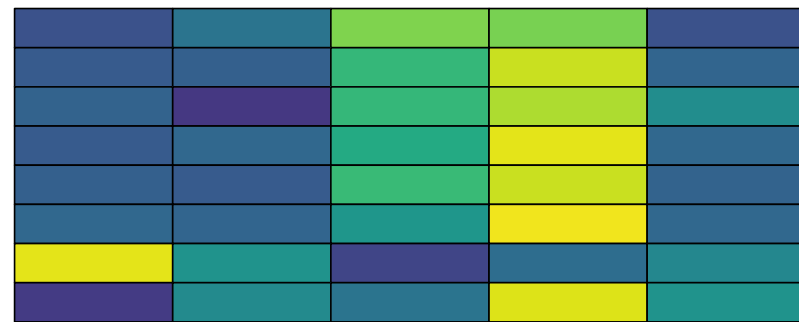

$\mathrm{IL}-1 \alpha$ Female

IL-1 $\alpha$ Male

IL-1 $\beta$ Female

IL $-1 \beta$ Male

IL-6 Female

IL-6 Male

IL-10 Female

IL-10 Male

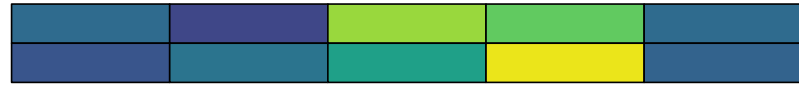

TNF $\alpha$ Female

TNF $\alpha$ Male

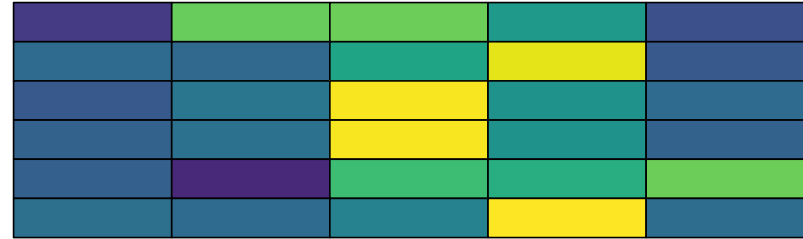

IFN $\alpha$ Female

IFN $\alpha$ Male

IFN $\beta$ Female

IFN $\beta$ Male

IFN $\gamma$ Female

IFN $\gamma$ Male

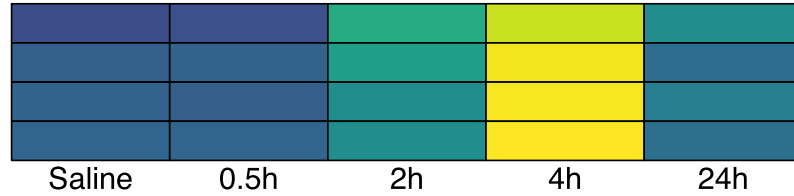

CCL2 Female

CCL2 Male

CXCL10 Female

CXCL10 Male

B.

\section{Protein Data}
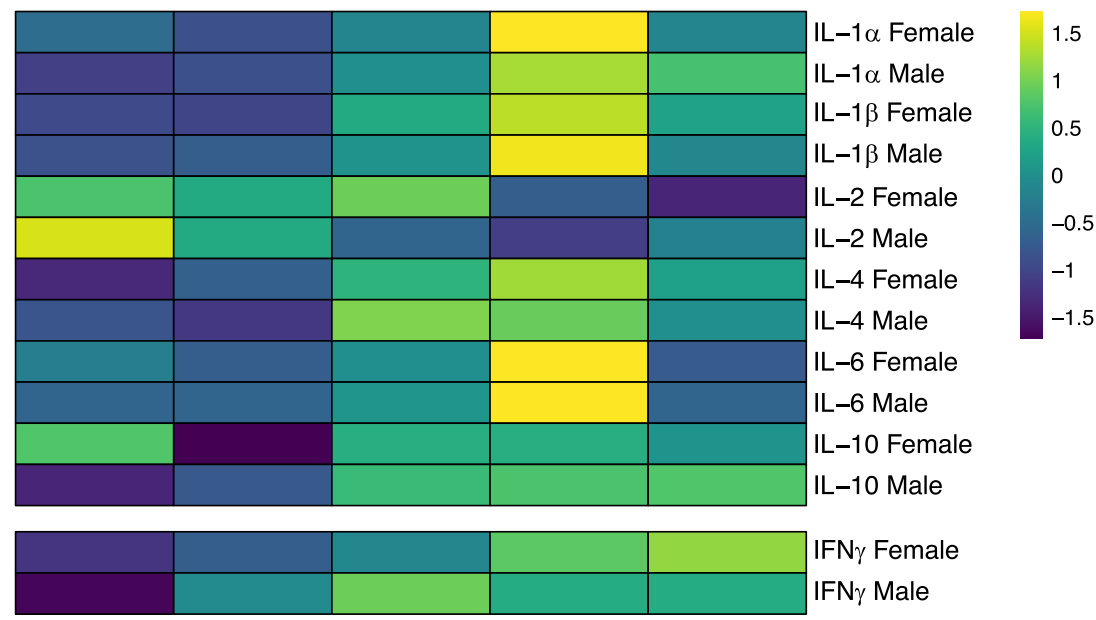

IFN $\gamma$ Female

IFN $\gamma$ Male

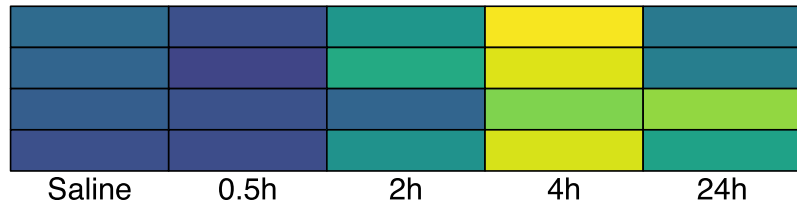

CCL2 Female

CCL2 Male

CXCL10 Female

CXCL10 Male

Saline

$0.5 h$

$2 \mathrm{~h}$

4h

24h

Fig. 5 Heatmaps of gene expression and protein levels in the hippocampus. Changes in A mRNA gene expression and $\mathbf{B}$ protein levels for cytokines, chemokines, and markers of glial activation are shown. Values are centered and scaled across rows to highlight changes across the time course for each gene of interest; thus, differences in magnitude between genes are not depicted 
immediate phase following poly I:C treatment peaked at 4h for both mRNA expression (Fig. 5A) and protein levels (Fig. 5B) and returned to levels of saline-treated animals by $24 \mathrm{~h}$ post-infusion.

\section{Discussion}

Here, we demonstrated that after central administration of poly I:C sufficient to induce acute physiological sickness (fever, weight loss) responses in both sexes, male and female mice showed acute hippocampal cytokine and chemokine elevations, as measured by both mRNA expression and protein levels, that followed the time course of fever. Interestingly, mRNA gene expression of

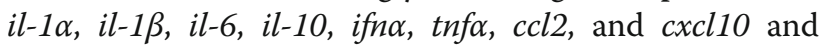
protein levels of CCL2 and CXCL10 showed a stronger response in males compared with females. Further, gene expression of il-10, ifn $\alpha$, and ifny increased in males only.

Poly I:C treatment in both sexes resulted in a significant and transient increase in hippocampal gene expression and protein levels of most, but not all, cytokines and chemokines measured, including IFN $\beta$, IL- $1 \alpha$, IL- $1 \beta$, IL-6, TNF $\alpha$, CCL2, and CXCL10. That administration of an immune stimulant, including viral mimics such as poly $\mathrm{I}: \mathrm{C}$, induces a neuroimmune response is not new; however, most of the previous studies on poly I:C used peripheral administration [74-77]. As such, multiple, indirect mechanisms are likely involved in causing inflammation in the brain [41]. Peripheral administration of poly I:C, specifically, was found to induce neuroinflammation through a separate and distinct pathway than central administration [57]. Thus, ICV poly I:C administration is one way to study sex differences and similarities in the neuroimmune response to a TLR3 agonist, without initial interference from sex-specific peripheral response. Additionally, we extend previous work to include a broader set of cytokines and chemokines, including CCL2 and CXCL10, and type I interferons that typically respond to viruses. Given evidence of mechanistic complexities governing neuroimmune activation, particularly from stimulants such as poly I:C, and given that there are over 300 cytokines with important roles in the immune system and neural function, it is critical to begin looking beyond IL-1 $\beta$, IL-6, and TNF $\alpha$ and more strongly consider implications of such limits in experimental design for the field of psychoneuroimmunology.

Males and females differ in immune responses, and the direction of these differences depends on whether one is looking in the periphery [13] or the brain [32,33] and whether the immune challenge itself is systemic or brain-specific. We found that mRNA gene expression of $i l-1 \alpha, i l-1 \beta$, il-6, il-10, ifn $\alpha$, tnf $\alpha, c c l 2$, and $\operatorname{cxcl10}$ and protein levels of CCL2 and CXCL10 in the hippocampus showed a stronger response in males compared with females. A greater magnitude of cytokine and chemokine response in males is consistent with previous findings that male-derived astrocytes have a greater reaction to inflammatory insults compared with females $[32,33,78$, 79].

Poly I:C is recognized by microglia, astrocytes, and neurons via toll-like receptor 3 (TLR3) [80-82]. The interaction of these 3 cell types is crucial in mediating inflammatory responses [83, 84]. Given that TLR3 shows much greater expression in astrocytes relative to microglia [85], we speculate that the reaction of astrocytes in males may be driving the sex differences in magnitude gene expression response of cytokines following poly I:C. The astrocyte activation marker, GFAP, and the microglial activation marker, CD11b, did not increase until 24 $\mathrm{h}$ after poly I:C treatment and did not show sex differences. However, this does not absolve astrocytes or microglia from the acute response to poly I:C. Specifically, Norden and colleagues found that cytokine gene expression from both astrocytes and microglia preceded increases in astrocyte and microglial activation markers, (GFAP and Iba1, respectively), and that these activation markers similarly did not show reliable increases until the 24-h time point [86]. Further work is needed to understand how neuroimmune cells, and in particular astrocytes, drive sex differences in cytokine response to poly I:C.

We observed that for most cytokines examined here, males showed a greater response to poly I:C than did females. Whereas others have reported increases in select inflammatory markers following poly I:C treatment, these studies used either only used male $[75,76]$ or female rodents [74, 77]. To the best of our knowledge, this is the first direct comparison of hippocampal cytokines in males and females as a consequence of poly I:C. Whether the greater magnitude in male response to poly I:C indicates greater neuroprotection or vulnerability to cognitive dysfunction is yet to be determined.

A critical question, arising from our observation of greater baseline mRNA expression and protein levels of cytokines and chemokines in females relative to males, is what is the biological relevance of these differences, and how do they relate to activated neuroimmune states? One possibility is that females mount a greater immune response to help clear viral loads and recover faster [38, 87-89], and also start out with greater immune activity that allows them to reach necessary activation states faster than males. Perhaps females do not need to have as strong of an activated response because they already have "more players in the game". This layer of nuance for understanding sex differences in immune/neuroimmune function adds to the broader notion that sex differences are not just about who has a stronger response, but that the type and pattern of response matters [26, 
34], together with the context (e.g., dose, type of challenge, timing, hormonal states $[13,34,88,90]$ ) all of which contribute to the complexity of understanding sex differences and their functional implications. Future work will need to address whether and how sex differences in the cytokine and chemokine basal levels or activation in response to immune challenge result in modulation of neural function and contribute to sexbiases in neurological and psychiatric disease.

Of particular note, we observed a sex-specific pattern of expression of the interferon family of cytokines in the hippocampus. Specifically, males showed increases in IFN $\alpha$, IFN $\beta$, and IFN $\gamma$, but females only showed a significant response in IFN $\beta$. This is consistent with previous findings that showed increased gene expression of IFN $\beta$, but not IFN $\alpha$, in females in response to peripheral poly I:C, though this study did not measure these effects in males for comparison [77]. Type I interferons, IFNa and IFN $\beta$, are key to the anti-viral response of the immune system and, as such, are known to respond to viral stimulants including poly I:C [54, 91-94]. Consistent with our data, in which IFN $\beta$ showed an early peak expression levels, type I interferon activity is responsible for inducing inflammatory cytokines such as IL-6 and TNF $\alpha$ [75, 77]. Additionally, interferon signaling from poly I:C treatment also results in altered glutamatergic signaling [91, 92], which is critical for hippocampal memory formation [95]. One caveat is that we only measured IFN $\alpha$ and IFN $\beta$ gene expression. Nevertheless, other studies have demonstrated a correspondence of increased IFN $\beta$ gene expression and modulation of memory in females [58, 77]. Thus, given that males show increased expression of both IFN $\alpha$ and IFN $\beta$ in the hippocampus following poly I:C whereas females only induce IFN $\beta$, together with the roles of IFN $\beta$ in learning and memory, interferon-related signaling is likely key for understanding sex differences in virus, or virus-like, modulation of memory and cognition.

This study characterized the neuroimmune and sickness responses to central administration of poly I:C, and we observed sex-specific patterns of hippocampal cytokine transcription and translational responses. Specifically, we identified type I interferons as one potential node mediating sex-specific cytokine responses and neuroimmune effects on synaptic plasticity and cognition. Additionally, the magnitude of response of cytokines such as CCL2 and CXCL10 highlight the importance of future work incorporating a more comprehensive set of inflammatory markers using multiple endpoints. Neuroimmune activation is known to play a role in cognitive deficits and affective dysregulation in diseases such as Alzheimer's disease and other dementias [96], Posttraumatic stress disorder [97, 98], depression [11, 99], and now also COVID-19 [100]. Given the sex/gender biases in prevalence, severity, and/or survival outcomes, identifying sex-specific neuroimmune responses will provide novel targets for personalized prevention and treatment of these diseases.

\section{Abbreviations \\ CCL2: C-C motif chemokine ligand 2; Cd1 1 b: Cluster of differentiation molecule 11b; CXCL10: C-X-C motif chemokine ligand; COVID-19: Coronavirus disease 2019; GFAP: Glial fibrillary acidic protein; ICV: Intracerebroventricular; IFN: Interferon; IL: Interleukin; LPS: Lipopolysaccharide; mRNA: Messenger ribonucleic acid; Poly I:C: Polyinosinic:polycytidylic acid; qPCR: Quantitative polymerase chain reaction; TNFa: Tumor necrosis factor a}

\section{Acknowledgements}

We would like to thank Dr. Ashley Keiser, Dr. Daria Tchessalova, Brynne Raines, and Sarah Jacob for the assistance with the techniques, reagents, and data collection for these experiments. We would also like to thank Dr.

Shigeki Iwase for lending lab space and equipment to carry out the PCR experiments in the study.

\section{Authors' contributions}

CKP designed the experiments, performed all animal surgeries and treatments, collected physiological measurements (body temperature and weights) and tissue, processed tissue samples and conducted all molecular biology assays (qPCR and multiplex assays), ran statistical analyses, and wrote the manuscript. RGH aided in the collection of physiological measurements (body temperature and weights) and monitored animals for sickness

behaviors and surgical recovery throughout the experiments. NCT provided intellectual contributions regarding experimental design and data interpretation, supplied financial support and laboratory space and equipment to complete the experiments, and contributed significantly to the editing of this manuscript. All authors read and approved the final version of this manuscript.

\section{Authors' information}

CKP is trained in behavioral neuroscience with specific interests in behavioral neuroimmunology. Since 2013, CKP has worked on models of neuroimmune activation in both rats and mice with the goal of understanding how the neuroimmune system functions to modulate cognition and affect and both whether and how biological sex interacts with these processes.

NCT studies the mechanisms of learning and memory in males and females, the modulation of memory and affective processes by neuroimmune activation, and long-term impact of illness on the hippocampus, cognitive decline, Alzheimer's disease, and neuropsychiatric disorders.

\section{Funding}

These experiments were supported by a University of Michigan Office of Research Award to NCT. This funding body did not provide input for the design of the study, collection, analysis, data interpretation, or writing of this manuscript. The award was used solely to fund the cost of animals, reagents, and equipment in these experiments.

\section{Availability of data and materials}

The data used and analyzed for the current study are available from the corresponding author upon reasonable request.

\section{Declarations}

Ethics approval and consent to participate

All animal protocols used in these experiments were approved by the Institutional Animal Care and Use Committee (IACUC) at the University of Michigan.

\section{Consent for publication}

Not applicable

Competing interests

The authors declare that they have no competing interests. 
Received: 15 March 2021 Accepted: 4 August 2021

Published online: 06 September 2021

\section{References}

1. Hart BL. Biological basis of the behavior of sick animals. Neurosci Biobehav Rev. 1988;12(2):123-37. https://doi.org/10.1016/S0149-7634(88)80004-6.

2. Dantzer R. Cytokine-induced sickness behaviour: a neuroimmune response to activation of innate immunity. Eur J Pharmacol. 2004;500(1-3):399-411. https://doi.org/10.1016/J.EJPHAR.2004.07.040

3. Marin I, Kipnis J. Learning and memory ... and the immune system. Learn Mem. 2013;20(10):601-6. https://doi.org/10.1101//m.028357.112.

4. Rizzo FR, Musella A, De Vito F, et al. Tumor Necrosis Factor and Interleukin$1 \beta$ Modulate Synaptic Plasticity during Neuroinflammation. Neural Plast. 2018;2018:8430123-12. https://doi.org/10.1155/2018/8430123.

5. Yirmiya R, Goshen I. Immune modulation of learning, memory, neural plasticity and neurogenesis. Brain Behav Immun. 2011;25(2):181-213. https:// doi.org/10.1016/J.BBI.2010.10.015.

6. Pribiag $\mathrm{H}$, Stellwagen D. Neuroimmune regulation of homeostatic synaptic plasticity. Neuropharmacology. 2014;78(C):13-22. https://doi.org/10.1016/J. NEUROPHARM.2013.06.008

7. Barrientos RM, Frank MG, Watkins LR, Maier SF. Aging-related changes in neuroimmune-endocrine function: implications for hippocampal-dependent cognition. Horm Behav. 2012;62(3):219-27. https://doi.org/10.1016/j.yhbeh.2 012.02.010.

8. Dantzer R, O'Connor JC, Freund GG, Johnson RW, Kelley KW. From inflammation to sickness and depression: when the immune system subjugates the brain. Nat Rev Neurosci. 2008;9(1):46-56. https://doi.org/10.1 038/nrn2297.

9. Tchessalova D, Tronson NC. Enduring and Sex-specific Changes in Hippocampal Gene Expression after a Subchronic Immune Challenge. Neuroscience. 2020;428:76-89. https://doi.org/10.1016/j.neuroscience.201 9.12.019.

10. Tchessalova D, Tronson NC. Memory deficits in males and females long after subchronic immune challenge. Neurobiol Learn Mem. 2019;158:60-72. https://doi.org/10.1016/J.NLM.2019.01.003.

11. Bekhbat M, Neigh GN. Sex differences in the neuro-immune consequences of stress: Focus on depression and anxiety. Brain Behav Immun. 2018;67:112. https://doi.org/10.1016/j.bbi.2017.02.006.

12. Neigh GN, Bekhbat M, Rowson SA. Neuroimmunology: behavioral effects. Oxford Research Encyclopedias: Neuroscience. Oxford University Press. Online. 2018. https://doi.org/10.1093/ACREFORE/9780190264086.013.7

13. Klein SL, Flanagan KL. Sex differences in immune responses. Nat Rev Immunol. 2016;16(10):626-38. https://doi.org/10.1038/nri.2016.90.

14. Klein SL, Huber S. Sex differences in susceptibility to viral infection. In: Klein SL, Robers C, editors. Sex Hormones and Immunity to Infection. Berlin Heidelberg: Springer-Verlag; 2010. p. 93-122. https://doi.org/10.1007/978-3642-02155-8_4

15. Ransohoff RM. Chemokines and chemokine receptors: standing at the crossroads of immunobiology and neurobiology. Immunity. 2009;31(5):71121. https://doi.org/10.1016/j.immuni.2009.09.010.

16. Ransohoff RM, Brown MA. Innate immunity in the central nervous system. J Clin Invest. 2012;122(4):1164-71. https://doi.org/10.1172/JCI58644.

17. Barrientos RM, O'Reilly RC, Rudy JW. Memory for context is impaired by a post context exposure injection of interleukin-1 beta into dorsal hippocampus. Behav Brain Res. 2002;134(1-2):291-8. https://doi.org/10.1016/ S0166-4328(02)00043-8.

18. Goshen I, Kreisel T, Ounallah-Saad H, Renbaum P, Zalzstein Y, Ben-Hur T, et al. A dual role for interleukin-1 in hippocampal-dependent memory processes. Psychoneuroendocrinology. 2007;32(8-10):1106-15. https://doi. org/10.1016/J.PSYNEUEN.2007.09.004.

19. Yirmiya R, Winocur G, Goshen I. Brain interleukin-1 is involved in spatial memory and passive avoidance conditioning. Neurobiol Learn Mem. 2002; 78(2):379-89. https://doi.org/10.1006/nlme.2002.4072.

20. Sparkman NL, Buchanan JB, Heyen JRR, Chen J, Beverly JL, Johnson RW. Interleukin-6 facilitates lipopolysaccharide-induced disruption in working memory and expression of other proinflammatory cytokines in hippocampal neuronal cell layers. J Neurosci. 2006;26(42):10709-16. https:// doi.org/10.1523/JNEUROSCI.3376-06.2006.

21. Trapero I, Cauli O. Interleukin 6 and cognitive dysfunction. Metab Brain Dis. 2014;29(3):593-608. https://doi.org/10.1007/s11011-014-9551-2.
22. Weaver JD, Huang MH, Albert M, Harris T, Rowe JW, Seeman TE. Interleukin6 and risk of cognitive decline: Macarthur studies of successful aging. Neurology. 2002;59(3):371-8. https://doi.org/10.1212/WNL.59.3.371.

23. Feuerstein GZ, Liu T, Barone FC. Cytokines, inflammation, and brain injury: Role of tumor necrosis factor-alpha. Cerebrovasc Brain Metab Rev. 1994;6(4): 341-60 https://europepmc.org/article/med/7880718.

24. Lindbergh CA, Casaletto KB, Staffaroni AM, Elahi F, Walters SM, You M, et al. Systemic Tumor Necrosis Factor-Alpha Trajectories Relate to Brain Health in Typically Aging Older Adults. J Gerontol A Biol Sci Med Sci. 2020;75(8):155865. https://doi.org/10.1093/gerona/glz209.

25. Strieter RM, Kunkel SL, Bone RC. Role of tumor necrosis factor-a in disease states and inflammation. Crit Care Med. 1993;21(10 SUPPL):S447-63. https:// doi.org/10.1097/00003246-199310001-00006.

26. Donzis EJ, Tronson NC. Modulation of learning and memory by cytokines: Signaling mechanisms and long term consequences. Neurobiol Learn Mem. 2014;115:68-77. https://doi.org/10.1016/J.NLM.2014.08.008.

27. Blank T, Detje CN, Spieß A, Hagemeyer N, Brendecke SM, Wolfart J, et al. Brain Endothelial- and Epithelial-Specific Interferon Receptor Chain 1 Drives Virus-Induced Sickness Behavior and Cognitive Impairment. Immunity. 2016; 44(4):901-12. https://doi.org/10.1016/j.immuni.2016.04.005.

28. Westin K, Buchhave $P$, Nielsen $H$, Minthon L, Janciauskiene $S$, Hansson $O$. CCL2 is associated with a faster rate of cognitive decline during early stages of Alzheimer's disease. Ginsberg SD, ed. PLoS One. 2012;7(1):e30525. https:// doi.org/10.1371/journal.pone.0030525.

29. Xu J, Dong H, Qian Q, Zhang X, Wang Y, Jin W, et al. Astrocyte-derived CCL2 participates in surgery-induced cognitive dysfunction and neuroinflammation via evoking microglia activation. Behav Brain Res. 2017; 332:145-53. https://doi.org/10.1016/j.bbr.2017.05.066.

30. Bajova H, Nelson TE, Gruol DL. Chronic CXCL10 alters the level of activated ERK1/2 and transcriptional factors CREB and NF-KB in hippocampal neuronal cell culture. J Neuroimmunol. 2008;195(1-2):36-46. https://doi.org/10.1016/j. jneuroim.2008.01.003.

31. Bradburn S, McPhee J, Bagley L, Carroll M, Slevin M, al-Shanti N, et al. Dysregulation of C-X-C motif ligand 10 during aging and association with cognitive performance. Neurobiol Aging. 2018;63:54-64. https://doi.org/10.1 016/j.neurobiolaging.2017.11.009.

32. Loram LC, Sholar PW, Taylor FR, Wiesler JL, Babb JA, Strand KA, et al. Sex and estradiol influence glial pro-inflammatory responses to lipopolysaccharide in rats. Psychoneuroendocrinology. 2012;37(10):1688-99. https://doi.org/10.1016/j.psyneuen.2012.02.018.

33. Santos-Galindo M, Acaz-Fonseca E, Bellini MJ, Garcia-Segura LM. Sex differences in the inflammatory response of primary astrocytes to lipopolysaccharide. Biol Sex Differ. 2011;2(1):7. https://doi.org/10.1186/20426410-2-7.

34. Speirs IC, Tronson NC. Sex differences in hippocampal cytokines after systemic immune challenge. bioRxiv. 2018:378257. https://doi.org/10.1101/3 78257.

35. Bettcher BM, Neuhaus J, Wynn MJ, et al. Increases in a pro-inflammatory chemokine, MCP-1, are related to decreases in memory over time. Front Aging Neurosci. 2019;11:25. https://doi.org/10.3389/fnagi.2019.00025.

36. Richwine AF, Sparkman NL, Dilger RN, Buchanan JB, Johnson RW. Cognitive deficits in interleukin-10-deficient mice after peripheral injection of lipopolysaccharide. Brain Behav Immun. 2009;23(6):794-802. https://doi. org/10.1016/j.bbi.2009.02.020.

37. Kronfol Z, Remick DG. Cytokines and the brain: Implications for clinical psychiatry. Am J Psychiatry. 2000;157(5):683-94. https://doi.org/10.1176/a ppi.ajp.157.5.683.

38. Barna M, Komatsu T, Bi Z, Reiss CS. Sex differences in susceptibility to viral infection of the central nervous system. J Neuroimmunol. 1996;67(1):31-9. https://doi.org/10.1016/0165-5728(96)00022-7.

39. Klein SL, Dhakal S, Ursin RL, Deshpande S, Sandberg K, Mauvais-Jarvis F. Biological sex impacts COVID-19 outcomes. PLoS Pathog. 2020;16(6): e1008570. https://doi.org/10.1371/journal.ppat.1008570.

40. Takahashi T, Ellingson MK, Wong $P$, et al. Sex differences in immune responses that underlie COVID-19 disease outcomes. Nature. 2020;588(7837): 315-20. https://doi.org/10.1038/s41586-020-2700-3.

41. Watkins LR, Maier SF, Goehler LE. Cytokine-to-brain communication: A review \& analysis of alternative mechanisms. Life Sci. 1995;57(11):1011-26. https://doi.org/10.1016/0024-3205(95)02047-M.

42. Cunningham C, Campion S, Lunnon K, Murray CL, Woods JFC, Deacon RMJ, et al. Systemic inflammation induces acute behavioral and cognitive 
changes and accelerates neurodegenerative disease. Biol Psychiatry. 2009; 65(4):304-12. https://doi.org/10.1016/j.biopsych.2008.07.024

43. Czerniawski J, Guzowski JF. Acute neuroinflammation impairs context discrimination memory and disrupts pattern separation processes in hippocampus. J Neurosci. 2014;34(37):12470-80. https://doi.org/10.1523/ JNEUROSCI.0542-14.2014.

44. McAfoose J, Baune BT. Evidence for a cytokine model of cognitive function. Neurosci Biobehav Rev. 2009;33(3):355-66. https://doi.org/10.1016/j. neubiorev.2008.10.005

45. Vasek MJ, Garber C, Dorsey D, Durrant DM, Bollman B, Soung A, et al. A complement-microglial axis drives synapse loss during virus-induced memory impairment. Nature. 2016;534(7608):538-43. https://doi.org/10.103 8/nature18283.

46. Koo JW, Duman RS. Evidence for IL-1 receptor blockade as a therapeutic strategy for the treatment of depression. Curr Opin Investig Drugs. 2009; 10(7):664-71. https://www.ncbi.nlm.nih.gov/pmc/articles/PMC3673287/.

47. Ming TM, Juan LW, Qin PY, Ting GX, Cong LY. Hippocampal neurogenesis dysfunction linked to depressive-like behaviors in a neuroinflammation induced model of depression. Physiol Behav. 2016;161:166-73. https://doi. org/10.1016/j.physbeh.2016.04.034.

48. Dantzer R. Cytokine, Sickness Behavior, and Depression. Immunol Allergy Clin North Am. 2009;29(2):247-64. https://doi.org/10.1016/J.IAC.2009.02.002

49. Koo JW, Duman RS. IL-1 $\beta$ is an essential mediator of the antineurogenic and anhedonic effects of stress. Proc Natl Acad Sci U S A. 2008;105(2):751-6. https://doi.org/10.1073/PNAS.0708092105.

50. Nolan Y, Maher FO, Martin DS, Clarke RM, Brady MT, Bolton AE, et al. Role of interleukin-4 in regulation of age-related inflammatory changes in the hippocampus. J Biol Chem. 2005;280(10):9354-62. https://doi.org/10.1074/ jbc.M412170200.

51. Gadani SP, Cronk JC, Norris GT, Kipnis J. IL-4 in the brain: a cytokine to remember. J Immunol. 2012;189(9):4213-9. https://doi.org/10.4049/ jimmunol.1202246.

52. Petitto JM, McCarthy DB, Rinker CM, Huang Z, Getty T. Modulation of behavioral and neurochemical measures of forebrain dopamine function in mice by species-specific interleukin-2. J Neuroimmunol. 1997;73(1-2):183-90. https://doi.org/10.1016/S0165-5728(96)00196-8.

53. Gruol DL. Impact of Increased Astrocyte Expression of IL-6, CCL2 or CXCL10 in Transgenic Mice on Hippocampal Synaptic Function; 2016. https://doi. org/10.3390/brainsci6020019.

54. Teijaro JR. Type i interferons in viral control and immune regulation. Curr Opin Virol. 2016;16:31-40. https://doi.org/10.1016/j.coviro.2016.01.001.

55. Akiyama $\mathrm{H}, \mathrm{McGeer} \mathrm{PL}$. Brain microglia constitutively express $\beta-2$ integrins. J Neuroimmunol. 1990;30(1):81-93. https://doi.org/10.1016/0165-572 8(90)90055-R.

56. Eng LF, Ghirnikar RS. GFAP and Astrogliosis. Brain Pathol. 1994;4(3):229-37. https://doi.org/10.1111/j.1750-3639.1994.tb00838.x.

57. Zhu X, Levasseur PR, Michaelis KA, Burfeind KG, Marks DL. A distinct brain pathway links viral RNA exposure to sickness behavior. Sci Rep. 2016;6(1): 29885. https://doi.org/10.1038/srep29885.

58. McGarry N, Murray CL, Garvey S, Wilkinson A, Tortorelli L, Ryan L, et al. Double stranded RNA drives anti-viral innate immune responses, sickness behavior and cognitive dysfunction dependent on dsRNA length, IFNAR1 expression and age. Brain Behav Immun. 2021;95:413-28. https://doi.org/1 0.1016/J.BBI.2021.04.016.

59. Hart BL. The behavior of sick animals. Vet Clin North Am Small Anim Pract 1991;21(2):225-37. https://doi.org/10.1016/S0195-5616(91)50028-0.

60. Silver N, Best S, Jiang J, Thein SL. Selection of housekeeping genes for gene expression studies in human reticulocytes using real-time PCR. BMC Mol Biol. 2006;7(1):33. https://doi.org/10.1186/1471-2199-7-33.

61. Vandesompele J, De Preter K, Pattyn F, et al. Accurate normalization of realtime quantitative RT-PCR data by geometric averaging of multiple internal control genes. Genome Biol. 2002;3(7):research0034. https://doi.org/10.1186/ gb-2002-3-7-research0034.

62. Perkins JR, Dawes JM, McMahon SB, Bennett DLH, Orengo C, Kohl M. ReadqPCR and NormqPCR: $R$ packages for the reading, quality checking and normalisation of RT-qPCR quantification cycle (Cq) data. BMC Genomics. 2012;13(1):296. https://doi.org/10.1186/1471-2164-13-296.

63. Andersen $\mathrm{CL}$, Jensen JL, Ørntoft TF. Normalization of real-time quantitative reverse transcription-PCR data: A model-based variance estimation approach to identify genes suited for normalization, applied to bladder and colon cancer data sets. Cancer Res. 2004;64(15):5245-50. https://doi.org/1 0.1158/0008-5472.CAN-04-0496.

64. Wickham H, Francois R, Henry L, Muller K. dplyr: A Grammar of Data Manipulation; 2020.

65. Wickham H, Henry L. tidyr: Tidy Messy Data; 2020.

66. Kassambara A. rstatix: pipe-friendly framework for basic statistical tests. 2020 https://cran.r-project.org/package=rstatix.

67. Signorell A, Aho K, Alfons A, et al. DescTools: tools for descriptive statistics. 2020.

68. Ludecke D. sjstats: Statistical functions for regression models; 2020.

69. Wickham H. ggplot2: Elegant Graphics for Data Analysis; 2016.

70. Auguie B. gridExtra: Miscellaneous Functions for "Grid" Graphics; 2017.

71. Kolde R. pheatmap: Pretty Heatmaps; 2019.

72. Garnier S. viridis: Default Color Maps from "matplotlib."; 2018.

73. Flannery LE, Henry RJ, Kerr DM, Finn DP, Roche M. FAAH, but not MAGL, inhibition modulates acute TLR3-induced neuroimmune signaling in the rat, independent of sex. J Neurosci Res. 2018;96(6):989-1001. https://doi.org/10.1 002/JNR.24120.

74. Cunningham C, Campion S, Teeling J, Felton L, Perry VH. The sickness behaviour and CNS inflammatory mediator profile induced by systemic challenge of mice with synthetic double-stranded RNA (poly I:C). Brain Behav Immun. 2007;21(4):490-502. https://doi.org/10.1016/J.BBI.2006.12.007.

75. Fortier ME, Kent S, Ashdown H, Poole S, Boksa P, Luheshi GN. The viral mimic, polyinosinic:polycytidylic acid, induces fever in rats via an interleukin-1-dependent mechanism. Am J Physiol - Regul Integr Comp Physiol. 2004;287(4 56-4):759-66. https://doi.org/10.1152/ajpregu.00293.2004.

76. Kamerman P, Skosana M, Loram L, Mitchell B, Weber J. Fever and inflammatory cytokine response in rats injected subcutaneously with viral double-stranded RNA analog, polyinosinic:polycytidylic acid (Poly-l:C). J Therm Biol. 2011;36(7):397-402. https://doi.org/10.1016/J.JTHERBIO.2011.07. 003.

77. Murray C, Griffin ÉW, O'Loughlin E, Lyons A, Sherwin E, Ahmed S, et al. Interdependent and independent roles of type I interferons and IL-6 in innate immune, neuroinflammatory and sickness behaviour responses to systemic poly I: C. Brain Behav Immun. 2015;48:274-86. https://doi.org/10.1 016/j.bbi.2015.04.009.

78. Astiz M, Acaz-Fonseca E, Garcia-Segura LM. Sex differences and effects of estrogenic compounds on the expression of inflammatory molecules by astrocytes exposed to the insecticide dimethoate. Neurotox Res. 2014;25(3): 271-85. https://doi.org/10.1007/s12640-013-9417-0.

79. Chistyakov DV, Azbukina NV, Astakhova AA, Goriainov SV, Chistyakov W, Sergeeva MG. Sex-mediated differences in Ips induced alterations of TNFa, IL-10 expression, and prostaglandin synthesis in primary astrocytes. Int J Mol Sci. 2018;19(9):2793. https://doi.org/10.3390/ijms19092793.

80. Alexopoulou L, Holt AC, Medzhitov R, Flavell RA. Recognition of doublestranded RNA and activation of NF-KB by Toll-like receptor 3. Nature. 2001; 413(6857):732-8. https://doi.org/10.1038/35099560.

81. Kielian T. Toll-like receptors in central nervous system glial inflammation and homeostasis. J Neurosci Res. 2006;83(5):711-30. https://doi.org/10.1002/ jnr.20767.

82. Matsumoto M, Seya T. TLR3: Interferon induction by double-stranded RNA including poly(l:C). Adv Drug Deliv Rev. 2008;60(7):805-12. https://doi.org/1 0.1016/J.ADDR.2007.11.005

83. Cerbai F, Lana D, Nosi D, Petkova-Kirova P, Zecchi S, Brothers HM, et al. The neuron-astrocyte-microglia triad in normal brain ageing and in a model of neuroinflammation in the rat hippocampus. PLoS One. 2012;7(9):e45250. https://doi.org/10.1371/journal.pone.0045250.

84. Scholz J, Woolf CJ. The neuropathic pain triad: neurons, immune cells and glia. Nat Neurosci. 2007;10(11):1361-8. https://doi.org/10.1038/nn1992.

85. Bsibsi M, Ravid R, Gveric D, Van Noort JM. Broad expression of Toll-like receptors in the human central nervous system. J Neuropathol Exp Neurol. 2002;61(11):1013-21. https://doi.org/10.1093/jnen/61.11.1013.

86. Norden DM, Trojanowski PJ, Villanueva E, Navarro E, Godbout JP. Sequential activation of microglia and astrocyte cytokine expression precedes increased iba-1 or GFAP immunoreactivity following systemic immune challenge. Glia. 2016;64(2):300-16. https://doi.org/10.1002/glia.22930.

87. Channappanavar R, Fett C, Mack M, Ten Eyck PP, Meyerholz DK, Perlman S. Sex-based differences in susceptibility to severe acute respiratory syndrome coronavirus infection. J Immunol. 2017;198(10):4046-53. https://doi.org/10.4 049/jimmunol.1601896. 
88. Klein SL. Sex influences immune responses to viruses, and efficacy of prophylaxis and treatments for viral diseases. BioEssays. 2012;34(12):1050-9. https://doi.org/10.1002/bies.201200099.

89. Vom Steeg $L G$, Klein SL. SeXX matters in infectious disease pathogenesis. PLoS Pathog. 2016;12(2):e1005374. https://doi.org/10.1371/journal.ppat.1 005374.

90. Coelho LCM, Cruz JV, Maba IK, Zampronio AR. Fever induced by Zymosan A and polyinosinic-polycytidylic acid in female rats: influence of sex hormones and the participation of endothelin-1. Inflammation. 2021;44(1):321-33. https://doi.org/10.1007/s10753-020-01335-5.

91. Costello DA, Lynch MA. Toll-like receptor 3 activation modulates hippocampal network excitability, via glial production of interferon- $\beta$. Hippocampus. 2013;23(8):696-707. https://doi.org/10.1002/hipo.22129.

92. Scumpia PO, Kelly KM, Reeves WH, Stevens BR. Double-stranded RNA signals antiviral and inflammatory programs and dysfunctional glutamate transport in TLR3-expressing astrocytes. Glia. 2005;52(2):153-62. https://doi.org/10.1 002/glia.20234.

93. Seth RB, Sun L, Chen ZJ. Antiviral innate immunity pathways. Cell Res. 2006; 16:141-7. https://doi.org/10.1038/sj.cr.7310019.

94. Stetson DB, Medzhitov R. Type I Interferons in Host Defense. Immunity. 2006;25(3):373-81. https://doi.org/10.1016/j.immuni.2006.08.007.

95. Katagiri H, Tanaka K, Manabe T. Requirement of appropriate glutamate concentrations in the synaptic cleft for hippocampal LTP induction. Eur J Neurosci. 2001;14(3):547-53. https://doi.org/10.1046/j.0953-816X.2001.01664. $x$.

96. Krstic D, Knuesel I. Deciphering the mechanism underlying late-onset Alzheimer disease. Nat Rev Neurol. 2013;9(1):25-34. https://doi.org/10.1038/ nrneurol.2012.236.

97. Pace TUW, Heim CM. A short review on the psychoneuroimmunology of posttraumatic stress disorder: From risk factors to medical comorbidities. Brain Behav Immun. 2011;25(1):6-13. https://doi.org/10.1016/J.BBI.2010.10. 003.

98. Wang Z, Young MRI. PTSD, a Disorder with an Immunological Component. Front Immunol. 2016;7:219. https://doi.org/10.3389/fimmu.2016.00219.

99. Hodes GE, Kana V, Menard C, Merad M, Russo SJ. Neuroimmune mechanisms of depression. Nat Neurosci. 2015;18(10):1386-93. https://doi. org/10.1038/nn.4113.

100. Zhou H, Lu S, Chen J, Wei N, Wang D, Lyu H, et al. The landscape of cognitive function in recovered COVID-19 patients. J Psychiatr Res. 2020;129: 98-102. https://doi.org/10.1016/j.jpsychires.2020.06.022.

\section{Publisher's Note}

Springer Nature remains neutral with regard to jurisdictional claims in published maps and institutional affiliations.

Ready to submit your research? Choose BMC and benefit from:

- fast, convenient online submission

- thorough peer review by experienced researchers in your field

- rapid publication on acceptance

- support for research data, including large and complex data types

- gold Open Access which fosters wider collaboration and increased citations

- maximum visibility for your research: over $100 \mathrm{M}$ website views per year

At $\mathrm{BMC}$, research is always in progress.

Learn more biomedcentral.com/submissions 